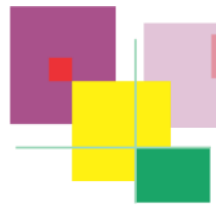

\title{
Panorama sociolinguístico do contato Português- Francês na fronteira Brasil-Guiana Francesa
}

\section{Sociolinguistic panorama of Portuguese-French contact on the Brazil-French Guiana border}

\section{Kelly Cristina Nascimento Day*}

\author{
UEAP
}

Resumo: Este artigo tem por objetivo apresentar reflexões acerca dos efeitos sociais e linguísticos aportados pelo contato português-francêscréole na fronteira franco-brasileira, tomando por base resultados de diferentes pesquisas de cunho sociolinguístico realizadas ao longo dos últimos 20 anos. Esta análise conjunta e articulada nos permite perceber como as dinâmicas linguístico-linguageiras dessa fronteira têm sido determinadas por critérios sociodemográficos e econômicos delimitadores, por sua vez, do uso compartimentalizado das línguas na região, bem como por limites linguístico-identitários que encontram na língua um elemento delimitador de território.

Palavras-chave: Fronteira linguística, Contato, Português-Francês.

Abstract: This article aims to present reflections on the social and linguistic effects of the Portuguese-French-Creole contact on the French-Brazilian border, based on the results of different sociolinguistic research conducted over the past 20 years. This joint and articulated analysis allows us to perceive how the linguisticlinguistic dynamics of this border have been determined by sociodemographic and economic criteria that delimit, in turn, the 
compartmentalized use of languages in the region, as well as by linguistic-identitarian boundaries that find in language a delimiting element of territory.

Keywords: Linguistic frontier, Contact, Portuguese-French.

\section{Introdução}

A diversidade linguística brasileira e seus contornos superlativos corroboram o estatuto de país multilíngue e multicultural do qual desfruta o Brasil. Em suas diversas e inequívocas situações de contato com línguas exógenas e endógenas, as fronteiras constituem comumente panoramas complexos de mesclagem social e linguística nos espaços limítrofes entre o Brasil e os demais países confluentes na América do sul.

A região fronteiriça Amapá - Guiana Francesa, no norte brasileiro, é uma das mais singulares quanto ao contato linguístico nas Américas. O traçado físico e simbólico que separa o Amapá da Guiana Francesa, constitui, ao mesmo tempo, a maior fronteira terrestre do território francês e uma fronteira de características peculiares no cenário fronteiriço brasileiro, reconhecidamente marcado pelo contato do português com línguas de expressão hispânica.

Na confluência de cerca de 700 quilômetros entre Brasil e França, delimitados em 1900 com a assinatura do Laudo Suíço ${ }^{1}$, as cidades de Oiapoque e Saint-Georges conformam um corredor de passagem fronteiriço marcado pela convivência de diferentes povos, múltiplas etnias e culturas diversas que se integram em uma constante relação de atração e repulsão, de encontro e desencontro, de amizade e animosidade, relação esta alimentada pelas práticas de defesa da territorialidade (DI MÉO, 1998) do Estado-nação, em ambos os lados da fronteira.

Nesse cenário, em que a fronteira política assinala um distanciamento espacial e, ao mesmo tempo, se apresenta enquanto linha de contato e intercâmbio, propomo-nos a lançar um olhar para a fronteira Brasil- França como fruto de uma produção determinada por uma socialização e um posicionamento de parte dos diferentes atores sociais nela envolvidos. 
Para essa discussão, trazemos uma primeira seção sobre a condição múltipla e complexa das fronteiras, seguida de uma breve apresentação da construção sócio-histórica da fronteira franco-brasileira. Na seção 3 fazemos uma caracterização e discussão dos efeitos sociolinguísticos do contato português-francês nas dinâmicas sociolinguageiras das diferentes comunidades de fala e exploramos alguns aspectos do silenciamento das línguas regionais a partir da paisagem linguística dos municípios de Oiapoque e Saint-Georges. Por fim, sintetizamos nossa leitura da fronteira refletindo sobre as condições sócio-históricas que deram os contornos atuais a essa fronteira.

\section{As fronteiras como espaços múltiplos e complexos}

Em uma perspectiva macro, as fronteiras remetem à noção de limite, de barreira, de interface à qual se vinculam questões de ordem política, econômica, territorial e identitária. Em nível micro, as fronteiras condensam as formatações dos arranjos socioculturais, econômicos e linguísticos na busca da elaboração do que Bhabha (2007) nomeia de terceiro espaço ou espaço de "integrabilidade", muitas vezes constituídos em bases socioeconômicas muito desiguais.

Compreendendo a fronteira como um fato social, Simmel (1999, p. 607) observa que "a fronteira não é um fato espacial com efeitos sociológicos, mas um fato sociológico que assume uma forma espacial", cuja percepção se dá segundo a ótica do lado em que se vive (ou se está), permeada que é de fatores diversos entre os quais os históricos, econômicos, geopolíticos e socioculturais.

Nesse sentido, as relações nascidas na perspectiva da noção de fronteira se mostram temporal e espacialmente marcadas, sendo fruto de uma produção histórica, dos contornos semânticos do traçado geográfico estabelecido e das relações de poder em jogo em cada zona fronteiriça.

Como bem destaca Weinreich (1970), as linhas divisórias que separam povos falantes de diferentes línguas, comumente coincidem com outras divisões de natureza não linguística (étnicas, raciais, religiosas, econômicas), sendo o limite geográfico só mais um dos fatores de convergência na organização social e linguística dos povos.

As regiões situadas ao longo das fronteiras têm suas próprias identidades e estas, normalmente, estão relacionadas com as 
necessidades e características inerentes ao contexto e à situação de proximidade com um país limítrofe. A fronteira, como espaço simbólico, é também fruto da capacidade de representação humana, e, no contexto da relação sujeito, linguagem e mundo a noção de fronteira passa pelo olhar e pelo lugar social de quem fala e dela se apropria.

É imperativo considerar ainda que na lógica do Estado-nação, na luta pela unidade cultural, diferentes instrumentos são empregados, dentre os quais a etnia, a religião, os traços culturais e a língua. A imposição do conhecimento dessa última é um dos meios mais utilizados na elaboração nacional do sentimento de pertencimento e de auto identificação de um grupo, razão pela qual a língua se torna, em si mesma, uma fronteira, um elemento capaz de delinear um território. Nos termos de Alvir; Gohard-Radenkovik,

Qualquer comunidade, para se proteger e se reafirmar, cria fronteiras internas. A lógica do Estado-nação era lutar pela unidade cultural da população nacional (...). Impor o conhecimento de uma língua comum, inventar e divulgar uma história nacional por meio de escolas e instituições acadêmicas, manter rituais e uma memória coletiva foram alguns dos instrumentos usados para criar a nação e despertar sentimentos de pertencimento (ALVIR; GOHARDRADENKOVIK, 2013, p. 60).

As fronteiras, nesse contexto, personificam a ideia de delimitação simbólica de identidade nacional, a partir de onde ficam estabelecidos critérios de quem se é e de que espaço social ${ }^{2}$ se habita. Ainda assim, na dinâmica das relações sociais 'entre linhas' divisórias, apropriar-se da fronteira, enquanto sujeito que a vivencia, implica, entre outras aderências, na adoção de práticas linguísticas plurais, originadas no contato inevitável e nas necessidades de comunicação entre grupos distintos.

As comunidades linguísticas, entendidas como "um conjunto de pessoas que interagem verbalmente e que compartilham um conjunto de normas com relação aos usos linguísticos" (ALKMIM, 2000, p. 31), em regiões limítrofes, entre nações, não raro estão situadas em redes 
comunicativas diversas, nas quais as práticas bilíngues ou multilíngues são a norma.

Cabe delimitar aqui, que as práticas bi/multilíngues concernem à capacidade do sujeito de funcionar em duas ou mais línguas de acordo com as exigências socioculturais de uma dada comunidade linguística (SKUTNABB-KANGAS, 1988). Para além disso, situamos as fronteiras no âmbito do multilinguismo societal, referindo a presença, em uma área geográfica específica - qualquer que seja o seu tamanho de mais do que uma "variedade de línguas" (...), sejam elas oficialmente reconhecidas como idioma ou não (LEGLISE, 2013, P.31).

Desse modo, compreende-se as fronteiras como espaços naturais de compartilhamento, cujas práticas de linguagem podem agir para o fortalecimento dos arranjos sociais locais ou acentuar as distâncias, especialmente quando as regras de comportamento verbal espelham divergências muito acentuadas. Dessa forma, se a proximidade permite que a cooperação se estabeleça no plano político, social e econômico, os conflitos, por outro lado, nem sempre são explícitos e se mostram, muitas vezes, através das representações e das ideias socialmente partilhadas no cotidiano das interações.

A elaboração de representações sobre o outro, entendidas nesse contexto como processos de construção partilhada de significados a partir da linguagem (HALL, 2003), aliada às atitudes, ou seja, aos posicionamentos positivos e negativos sobre um dado objeto (BOUDREAU, 2009), seja ele linguístico ou social, constituem processos inerentes às dinâmicas sociolinguísticas dos ambientes político-linguísticos limítrofes, contribuindo sobremaneira para a delimitação de uma identidade, tanto múltipla quanto socialmente marcada pelas diferentes matizes de sentidos e valores de grupos sociais diferentes.

Nesses cenários fronteiriços, os usos das línguas podem ou não ser fruto de uma escolha consciente, mas frequentemente são resultados inerentes às relações vivenciadas no cotidiano e aos contextos, particularmente, marcados nos quais estão inseridos os sujeitos. Assim, posto que "cada fronteira é uma fronteira" (OLIVEIRA, 2009) e as relações interpessoais nelas desenvolvidas carregam o peso e os traços de sua conformação, os fatos linguísticos dela derivados assumem os contornos que lhes concedem os enfrentamentos, as adesões e as interseções sociotemporais. 


\section{E por falar em fronteiras: uma breve sócio-história da construção da fronteira franco-brasileira}

A história do povoamento e posse do território que atualmente corresponde ao município de Oiapoque, na fronteira do Brasil com a Guiana francesa, se confunde com a própria história do contato português-francês nessa região.

De acordo com relatos dos mais antigos moradores, coletados por Romani (2010), Martinica seria o nome mais antigo atribuído à cidade de Oiapoque, em homenagem ao seu primeiro morador que teria sido um francês de origem martiniquense. O nome do município teria sido posteriormente alterado por Candido Rondon em 1936, em uma tentativa de apagar as influências externas da memória da comunidade. Se a história oficial desse rincão se inicia com a chegada dos militares brasileiros na década de 1920, a extraoficial parece ser muito mais fiel à memória afetiva que constitui a identidade dessa região e remonta a idos muito anteriores à chegada política do Estado brasileiro.

Romani registra que

(...) desde muito antes (...) do Estado brasileiro ter-se interessado pela colonização daquela região, seja por motivos econômicos ou de segurança nacional, já existia um fluxo natural de povoamento realizado pelas populações mais desprezadas dentro do conceito daquilo que vulgarmente se convencionou chamar de civilização (ROMANI, 2010, p.161).

O povoamento inicial da região, seja a brasileira, seja a guianense passa muito menos pelas estratégias de defesa do território que pela descoberta do ouro que atraiu aventureiros de ambos os lados da fronteira e impulsionou o litígio entre Brasil e França pelo domínio de parte do atual Estado do Amapá.

A figura do comerciante ambulante, o mascate, que circulava entre os garimpos e acampamentos intermediários na região do baixo Oiapoque, remete às primeiras iniciativas de criação de um entreposto comercial na zona limítrofe, a Martinica, bem como aos primeiros atores do contato linguístico português-francês na região. Sobre essa circulação, Romani (2010) revela que: 
Sabe-se de uma ligação terrestre entre o Counani e o Oiapoque, razoavelmente frequentada pela população local. Um trajeto que era realizado tanto pelos caboclos e negros brasileiros seguindo em direção ao norte, como pelos garimpeiros que vinham da Guiana Francesa (ROMANI, 2010, p.160).

Os efeitos dessa circulação se fazem mostrar também no protesto publicado na Folha da Noite, em novembro de 1920, por Augusto Lima, cujo autor denuncia "a ausência do Brasil daquela parte de seu território, onde só se fala o francês e circula o franco, com absoluta exclusão de homens e valores brasileiros" (DAY, 2013).

Hipoteticamente, é possível imaginar que a delimitação estabelecida no início do século XX tenha sido decisiva para a consolidação de dois sistemas linguísticos principais distintos: o da língua portuguesa e o da língua francesa, em um processo diferenciado daquele que teria ocorrido quando essa delimitação não estava definida, cuja mobilidade das populações indígenas e não indígenas deu origem aos crioulos de base francesa e portuguesa na região, como é o caso do Kheuól ${ }^{3}$ e do créole guianense ${ }^{4}$, falados atualmente em ambos os lados da fronteira.

Diferente do que relatam Sturza e Tatsch (2016) a respeito de uma identificação nascida da semelhança entre as culturas fronteiriças sul rio-grandense, argentina e uruguaia que contribuíra para o desenvolvimento da linguagem do gaúcho, a delimitação simbólica da fronteira franco-brasileira, através de uma limitação natural, o rio Oiapoque, e a presença do estado brasileiro e francês, de um lado e de outro do rio, visando assegurar a posse do território, pouco a pouco, alteraram sobremaneira o movimento de pessoas e, por conseguinte, reduziram a frequência do contato linguístico na região. Em face disso, o ambiente e a cultura amazônica comuns não parecem ter sido suficientes para agregar hábitos e costumes para a conformação de uma cultura franco-brasileira aproximativa.

O desenvolvimento das cidades de Oiapoque e Saint-Georges, ainda que com muitas similitudes, como a distância dos centros urbanos e o isolamento, ocorreu de modo bastante diverso, dada especialmente à condução política das instâncias nacionais, relegando-as à própria sorte, instigando as rivalidades e deslegitimando, com políticas de controle 
cada vez mais intensas, as relações outrora estabelecidas entre as comunidades.

A delimitação espacial deu origem a disfunções originadas pelas fraturas políticas e socioeconômicas que afetam, em especial as regiões justapostas díspares, ou seja, onde estruturas administrativas e controles jurídicos ou fiscais se mostram bastante assimétricos. Tais aspectos, aliados a disparidades monetárias e regimes sociais divergentes ${ }^{5}$ nessa fronteira, acabaram por reforçar as diferenças entre brasileiros e franceses ao longo da segunda metade do século XX.

Ao mesmo tempo, tais assimetrias sedimentaram, de um lado, uma identidade local de entreposto, de entre línguas, de culturas múltiplas em agregação, de lugar de passagem, onde a projeção imaginária de eldorado se encontra do outro lado do rio; e, de outro, a fronteira do exótico, do diferente, do abundante e do justo, cujas qualidades comparativas se quer alcançar. É nesse limiar que se justapõem as cidades de Oiapoque e Saint-Georges.

A elevação da ponte binacional, já no século XXI, provoca uma alteração significativa no ir e vir das catraias ${ }^{6}$ e no fluxo inerente da cultura regional que esse movimento simboliza, expondo ainda mais as lacerações políticas entre os estados nacionais a partir de um maior controle de passagem para o lado francês e, por conseguinte, da consolidação de uma total assimetria na circulação de pessoas e veículos entre um território e outro.

Essa configuração divergente, no entanto, não impediu o surgimento de uma comunidade bilíngue luso-francófona ou multilíngue (português/francês/língua crioula/língua indígena) de ambos os lados do rio. Nesse cenário sociopolítico um tanto caótico e difuso, as línguas funcionam como pontes entre desiguais, através das quais as comunidades suplantam as barreiras naturais e se encontram nas praças, no comércio, nos bares, nos barcos, nos restaurantes, nas ruas etc. e as práticas sociais se preenchem de sentidos singulares.

\section{A tessitura linguística da fronteira Amapá-Guiana Francesa}

$\mathrm{Na}$ literatura dos estudos linguísticos sobre as fronteiras brasileiras, a franco-brasileira é uma das menos conhecidas, porém não menos fecunda em termos de efeitos do contato linguístico. Embora essa região configure o encontro do português com diversas outras línguas, tal qual 
os crioulos de base francesa e portuguesa e de línguas indígenas ${ }^{7}$, este texto limitar-se-á ao contato português-francês e suas repercussões no ambiente sociolinguístico da fronteira, ainda que seus efeitos reverberem para as demais línguas.

Como já dissera Mackey (1976) as línguas em contato são situadas em uma relação de força e atração, cujo poder está vinculado ao contexto político, econômico e social em que se inserem, ou seja, aos povos que as utilizam, ao número de pessoas, suas riquezas, sua produção cultural, sua qualidade de vida, enfim, aspectos que corroboram o prestígio de uma língua em um dado contexto. De igual maneira, os efeitos do contato podem variar em função do espaço social ou geográfico que delimita a proximidade entre os povos, dos usos linguísticos e seus domínios, bem como das pressões que uma língua exerce sobre a outra.

Dito isso, e em função dos sabidos esforços dos governos nacionais para a manutenção de políticas monolíngues, pode-se afirmar que português e francês caracterizam-se como línguas hegemônicas nos respectivos territórios em que são línguas oficiais, o português em Oiapoque e o francês em Saint-Georges. Porém, os elementos que conformam o status de uma língua não são apenas jurídicos. A importância de uma língua está muito mais relacionada com a função que ela exerce enquanto veículo que permite a interação com aqueles que são importantes nos diversos domínios relacionados (comércio, religião, educação, ciência, cultura, esporte, lazer) do que com o ordenamento jurídico que a sustenta.

Nesse sentido, cabe destacar que o bilinguismo luso-francófono dessa região, especialmente o da comunidade não indígena, longe de ser um bilinguismo eletivo ${ }^{8}$ (VALDÉS; FIGUEROA, 1994), se vincula às dinâmicas interacionais intrínsecas à convivência e às condições socioeconômicas que contrapõem e aproximam as duas comunidades. Adicionar francês ou créole ao repertório linguístico dos fronteiriços não é uma escolha, mas uma condicionante do espaço social da fronteira.

Português e francês configuram, politicamente, forças em contraposição na região, ocupando valores simbólicos e relativos diferentes na percepção elaborada sobre o prestígio, função e status das línguas. Demograficamente, o português é a língua da ampla maioria, uma vez que a proporção populacional da fronteira é de 1(um) habitante 
em Saint-Georges para cada 6,3 habitantes em Oiapoque, porém, o fator demográfico não basta para determinar o status de uma língua, sendo só mais um dos elementos, podendo vir a ser atenuado por outros fatores.

O francês, em contrapartida, é a língua do mercado econômico fronteiriço, onde as transações em euro são fato comum e parte do cotidiano. Desse modo, é pertinente afirmar que o francês penetra o território brasileiro como fruto retroflexo da emigração de brasileiros para a Guiana Francesa e do papel econômico que a moeda européia desempenha nas relações comerciais fronteiriças.

Estudos diversos sobre as relações fronteiriças (SILVA, 2005; ROUMANI, 2010; ALMEIDA, RAUBER, 2017; entre outros) têm mostrado que tais aspectos, o demográfico e o econômico, atuam fortemente nos dois territórios e nos dois sentidos, ou seja, se influenciado mutuamente de dentro para fora e de fora para dentro, diluindo-se conforme a proximidade com a maior densidade populacional dos centros urbanos, Caiena e Macapá. Assim, a força demolinguística do português se mostra refletida na frequência com que esta configura-se como segunda língua ${ }^{9}$ (SPINASSE, 2006) na fronteira mais imediata do território francês que é Saint-Georges (LEGLISE, 2004) e se estende por todo o território guianense ora como língua materna, ora como segunda língua ou, ainda, como língua estrangeira ensinada nas escolas.

É relevante considerar, nesse contexto, o papel preponderante que a comunidade linguística francesa exerce no mercado econômico local, reverberando, portanto, para o mercado linguístico, nos termos de Bourdieu (1996). A língua francesa incorpora o valor do euro, o peso econômico da relação França-Brasil, do desenvolvimento regional, e, por conseguinte da clientela que abastece (a economia do município) e se abastece (de produtos e serviços) nessa relação simbiótica. Nesse cenário, a língua de prestígio do comércio local é o francês, tornandose, por conseguinte, um pré-requisito no mercado de trabalho e impulsionando o bilinguismo português-francês dos atores sociais locais.

Diferente de outras realidades, nas quais o Brasil se destaca frente a países sul-americanos cujas zonas comerciais se beneficiam do fluxo de brasileiros, como ocorre, por exemplo, na fronteira Brasil-Bolívia, Brasil-Paraguai, a ordem econômica se inverte na fronteira Brasil- 
Guiana Francesa, fazendo com que a desvalorização do real frente ao euro sirva de estímulo para um mercado mais vantajoso do lado brasileiro, atraindo assim uma parcela de franceses e de brasileiros erradicados na Guiana Francesa para esse mercado.

Essa circulação de brasileiros e franceses na região tem impacto direto no espaço urbano, através da presença visual e simbólica das línguas portuguesa e francesa, sobretudo do lado brasileiro da fronteira. As iniciativas individualizadas ou associativas apontando para uma integração linguística luso-francófona e observáveis através da paisagem linguística ${ }^{10}$ dos municípios, são reveladoras dessas conexões engendradas pelos vínculos históricos e socioeconômicos entre as comunidades de Oiapoque e Saint-Georges.

Normalmente conjugado com a língua portuguesa, o francês se mostra presente no nome dos estabelecimentos, no cardápio de restaurantes, na oferta de prestadores de serviço autônomos, em paineis publicitários de hotéis, entre outros. O valor simbólico de sua representação no território brasileiro se estende para além de aspectos relativos a status social, beleza ou atributo profissional.

A paisagem linguística de Oiapoque traz informações não apenas sobre o território em que se adentra, mas também aponta indícios sobre para quem ela se dirige, seu objetivo, informando igualmente sobre o poder econômico e de uso das línguas ali privilegiadas.

Conforme Bulot (2003), é importante ressaltar que o espaço urbano se configura também como "espaço discursivo" constituído por relações sociais e estruturas socioespaciais, cujas práticas linguísticas podem consolidar a proximidade ou ampliar as distâncias. Nesse sentido, a ausência das línguas crioulas e das línguas indígenas nos dois lados da fronteira aponta tanto para a relação de força entre as línguas quanto para as relações etnolinguísticas semiotizadas no espaço urbano.

A paisagem linguística nesses espaços contíguos situa o emprego das línguas no espaço urbano no contexto das escolhas linguísticas feitas tanto no plano governamental quanto no plano decisório das sociedades, corroborando a percepção de Hamel (2010) de que as políticas de linguagem podem nascer das iniciativas societais, sem ordenamento jurídico, porém impulsionadas por elementos inerentes ao próprio meio ambiente socioeconômico e cultural que o circunscreve.

Dentre os contextos sociolinguísticos nos quais a coexistência das línguas se mostra mais acentuada e evidente está a zona portuária e 
comercial do município de Oiapoque, caracterizadamente o terceiro espaço, onde grande parte dos trabalhadores formais e informais, tais como catraieiros, vendedores ambulantes, lojistas, atendentes, garçons, transportadores, carregadores, etc. são falantes de pelo menos duas línguas, ainda que o uso dessas línguas seja bastante compartimentalizado em diferentes domínios linguísticos e o bilinguismo constatado esteja relacionado especialmente à esfera laboral (DAY, 2005).

Nesse aspecto, a fronteira franco-brasileira se assemelha a tantas outras, onde a circulação de pessoas e suas práticas interativas assumem uma outra dinâmica. A diversidade linguística assume a faceta da naturalidade e as línguas se alternam conforme a necessidade, "independente do nível de domínio do código linguístico que cada um tem da língua do outro" (STURZA, 2010, p. 87).

Nessa linha, algumas pesquisas (DAY, 2005, 2012, 2013, 2019; PEREIRA, 2009; CALVET, 2009) têm mostrado que o bilinguismo da fronteira é impulsionado muito menos pelo desejo de aprender uma segunda língua em destaque no mercado linguístico mundial, como o inglês ou espanhol, do que pela necessidade local e urgente de inserirse em um contexto cuja língua proporcione maiores oportunidades de trabalho e de subsistência naquele ambiente, razão pela qual se explica um bilinguismo que se desenvolve, com frequência, na idade adulta dos falantes da fronteira (FUMELÊ; DAY, 2021) e em muitos casos, limitados à competência oral em domínios de uso muito específicos.

Em consonância, pesquisas mais recentes (SOUZA NASCIMENTO; DAY, 2021) indicam que o bilinguismo nessa região pouco ou quase nada tem a ver com níveis elevados de escolaridade, posto que grande parte dos bilíngues registra graus elementares de escolarização, contrastando com os agentes de setores públicos concursados, que prestam serviços demandados por brasileiros ou franceses e apresentam, comparativamente, um baixo domínio das línguas vizinhas, e por essa razão recorrem com maior frequência a instrumentos tecnológicos para realizar um atendimento em língua francesa no lado brasileiro da fronteira, quando se faz necessário.

Na contramão, em Saint-Georges, o português é mais usual no atendimento aos brasileiros monolíngues, especialmente nos setores públicos de controle da fronteira, nos correios e mesmo na prefeitura. Isso decorre, aparentemente, em função da baixa rotatividade no serviço 
público do lado francês e de uma forte exposição dos sujeitos, naquele território, ao uso da língua portuguesa, através das redes sociais que constituem (família, amigos, etc.).

Comumente, o alto grau de bilinguismo das regiões fronteiriças, competência necessária para esse viver entre línguas, advém da necessária e inerente construção de indivíduos polissociais (MACKEY, 1976) que tanto podem ter aderência a um grupo quanto a outro, em diferentes contextos. As práticas linguísticas mistas da fronteira francobrasileira carregam consigo não somente o status de uma língua e de outra, mas também as representações e os traços identitários nascidos de uma convivência nem sempre pacífica, "uma vez que nos embates sociais as escolhas linguísticas se manifestam e fazem surgir atitudes positivas ou negativas" (MELLO, 2011, p.142).

Ao tratar-se das competências multilíngues dos falantes dessa fronteira, hão de ser consideradas, portanto, as funções sociais distintivas que as línguas ocupam nas relações interpessoais, além das representações que agem quando se trata de informar quais línguas compõem o repertório linguístico de um falante. Declarar-se falante de francês, de créole guianense ou de Kheuól não é uma missão tão simples quanto pode parecer, à primeira vista. Qualquer observação sem critérios objetivos de análise vai passar à margem de uma percepção criteriosa sobre o sentido metafórico do uso das línguas, à medida que ser falante, por exemplo, de créole guianense e ainda mais do Kheuól, traz consigo o peso das línguas estigmatizadas e menos prestigiadas.

Para além disso, português, francês e os crioulos de base francesa e portuguesa, desenvolvem, nos termos de Calvet (2009) relações diglóssicas ${ }^{11}$ imbricadas onde variedade alta e baixa se alternam segundo o lado da fronteira, ocupando espaços linguísticos diferenciados, em que a transposição e a transgressão das condicionantes se revelam bastante complexas. A língua francesa, embora majoritária nos espaços oficiais e de contato entre grupos sociais distintos, tem uma difícil penetração nas interações entre os guianenses nos ambientes não formais. Do mesmo modo o créole não é comumente empregado nas interações de guianenses e franceses metropolitanos, entre guianenses e brasileiros, ou mesmo entre os demais grupos etnolinguísticos presentes no território francês, salvo quando se desenvolvem laços de amizade ou familiares entre esses grupos. 
Vale destacar que o créole guianense encerra uma representação simbólica de pertencimento, informando tanto sobre seu domínio territorial quanto sobre quem são seus falantes, fatores que delimitam quem, com quem e em quais circunstâncias pode-se fazer uso dessa língua. Os brasileiros que se inserem em grupos sociais além-fronteira, algumas vezes conseguem transpor as barreiras a acabam tornando-se falantes tanto do francês quanto do créole ou promovendo a mistura linguística dessas línguas, fato que também dificulta uma percepção objetiva das competências linguísticas em um ou outro idioma.

Decorrem daí fenômenos linguísticos recorrentes como a mistura de línguas, a alternância de códigos ou empréstimos lexicais que embora ainda não tenham sido investigados em profundidade, são ocorrências cotidianas facilmente observáveis na zona portuária das cidades de Oiapoque e Saint-Georges.

Outro aspecto a ser considerado na conformação dessa comunidade luso-francófona é a formação de famílias (mistas ou só de brasileiros), cujos filhos podem constituir uma das configurações linguísticas abaixo (DAY, 2005):

- Português e francês como língua materna e o créole guianense como segunda língua;

- Português como primeira língua, francês e créole como línguas segundas;

- Francês como primeira língua, português e créole como segunda língua;

- Português como primeira língua, créole como segunda língua e francês como língua de escolarização.

Tendo essas configurações como referência, é lícito afirmar que a língua francesa e o créole guianense, na condição de línguas maternas de um certo número de brasileiros dessa fronteira, também são línguas pertencentes ao espaço social fronteiriço brasileiro.

É relevante destacar, porém, que no âmbito da escolarização, é comum que crianças franco-brasileiras atravessem o rio para serem alfabetizadas no lado francês, porém o inverso raramente ocorre. $\mathrm{O}$ rigor e o controle observado na escolarização francesa, aliada aos programas $^{12}$ socioeconômicos vinculados, constituem-se também em 
atrativos para a manutenção dos estudantes nas escolas guianenses, tornando-se sustentáculos do plurilinguismo desses estudantes.

Particularmente, no que concerne ao ensino das línguas portuguesa e francesa no território vizinho, em 1996 foi assinado o Acordo de Cooperação Transfronteiriça entre os governos brasileiro e francês prevendo, entre outras ações conjuntas, a implementação do ensino do francês no Amapá, particularmente no Oiapoque, e do português na Guiana Francesa, porém, esse ensino, ainda que venha ocorrendo à margem da política de ensino de línguas no Brasil, ele não possui qualquer respaldo no ordenamento jurídico no lado brasileiro.

Chama atenção, nesse contexto, o fato de que a demanda social em torno dessas línguas não coaduna com as agendas sociais dos governos brasileiro e francês quando se trata de políticas linguísticas educativas. As línguas e o papel que desempenham nas relações 'entre grupos' e mesmo intragrupos, posto que o grupo social nem sempre se delimita pelo critério linguístico, parecem desempenhar funções sociais menos relevantes comparativamente à função política de defesa e delimitação de território, em que a língua é muito mais instrumento de controle de quem pode ou não ultrapassar a linha divisória do que veículo de interação e integração social.

Não surpreende, portanto, que não haja até então qualquer política linguística que regulamente o ensino do francês em Oiapoque, incentive o ensino de português em Saint-Georges ou que contemple os francobrasileiros com programas de educação integrados. As políticas observáveis são aquelas que advém das iniciativas individuais nos espaços públicos ou das famílias que optam por inserir seus filhos no sistema educacional francês.

A ausência de políticas linguísticas declaradas não aponta para a sua inexistência. No ordenamento jurídico, Amapá e Guiana Francesa, Brasil e França parecem virar as costas um para o outro e ignorar as dinâmicas interacionais existentes entre os povos da fronteira como uma tentativa dissimulada de desestimular, através da não formulação de políticas, o contato, a travessia e a emigração. Por outro lado, essa ausência, reforça os papeis simbólicos que português e francês têm desempenhado historicamente frente às demais línguas regionais. 


\section{Considerações Finais}

Encontrar caminhos para a satisfação das necessidades mais imediatas como a comunicação e a sobrevivência parece ser o primeiro elemento que conduz os indivíduos residentes em regiões fronteiriças ao encontro do outro, do diferente, do alternativo. Para a maioria das fronteiras nacionais o contato linguístico é um fenômeno que constitui, rotineiramente, sua história social, política e linguística. Os percursos delineados pelo uso das línguas se vinculam diretamente ao percurso sócio-histórico das comunidades e de seus falantes.

A confrontação linguística de duas línguas nacionais, hegemônicas em seus territórios e planejadas para consolidar duas nações monolíngues como é o caso de português e francês na fronteira francobrasileira nos mostra que o grupo linguístico majoritário nem sempre consegue transformar força demolinguística em prestígio, especialmente, quando as assimetrias entre os grupos sociais são de naturezas diversas (maior população de falantes versus maior poder econômico, por exemplo) e os conflitos se apresentam e se diluem em atitudes positivas e negativas, muitas vezes contraditórios.

O bilinguismo luso-francófono dessa fronteira origina-se na necessidade histórica de adaptação e convivência entre as comunidades brasileira e francesa, cuja conformação envolve, por um lado, práticas comerciais e interações sociais diversas, entre as quais aquelas emanadas pelo processo migratório, e por outro, a integração socioafetiva na constituição de famílias mistas, dando origem a diferentes configurações quanto ao processo de aquisição dessas línguas.

A condição prestigiosa de que desfruta a língua francesa na fronteira, ainda que em situação demográfica minoritária, é fruto também daquilo que simbolicamente ela pode proporcionar àqueles que através dela podem interagir com o grupo de maior poder econômico.

No sentido inverso, os falantes das línguas indígenas ou dos crioulos regionais, como falantes nativos de línguas minoritárias ou minorizadas, como é o caso do Kheuól e do créole guianense respectivamente, necessitam adaptar-se às práticas linguísticas estabelecidas nos centros urbanos que giram na maioria das vezes em torno de português e francês. 
Como consequência de um contato histórico e nada esporádico para quem vivencia a fronteira em sua face mais exposta, as interações bi/multilíngues português-francês, francês-créole ou português-créole constituem dinâmicas permeadas de sentidos sociais simbólicos, através dos quais estão delimitados valores espaço-territoriais, relacionais, interacionais e de status político-econômico, comumente evidenciados pela paisagem linguística dos municípios.

Assim, na simbiose da fronteira, esses valores acabam por estenderse, reconfigurando relações intragrupais, como é o caso da distinção feita aos brasileiros imigrantes falantes do créole como língua adicional, aos franco-brasileiros que tem francês e português como língua materna, aos franco-brasileiros-guianenses, cuja língua materna é o créole, e para os quais português e francês são respectivamente língua segunda e de escolarização. De igual maneira, a escolha linguística entre franceses e brasileiros passa pela distinção originada na margem oposta entre "les metrôs" e "les créoles", entre conhecidos e desconhecidos, que autoriza simbolicamente o uso de uma língua ou de outra.

Tais delimitações surgem permeadas de representações e atitudes favoráveis e desfavoráveis que tem em seu cerne a desconstrução alimentada pelas instâncias governamentais do sentido de fronteira enquanto espaço de unidade e integração sociocultural.

\section{Referências bibliográficas}

ALKMIN, T. "Sociolinguística". In: MUSSALIM, F.; BENTES, A. (Org.). Introdução a Linguística: Domínios e Fronteiras. São Paulo: Cortez Editora, p.21-47, 2000.

ALMEIDA, C.; RAUBER, A. "Oiapoque, aqui começa o Brasil: a fronteira em construção e os desafios do Desenvolvimento Regional". In: Redes, n.1, v. 22, p. 474 - 493. Santa Cruz do Sul: USCS, 2017. ALVIR, Spomenka; GOHARD-RADENKOVIC, Aline. (2013). "Quand les espaces - tiers révèlent les frontières... Et vice et versa". In: Cahiers internationaux de sociolinguistique, $n^{\circ}$ 4. p.57-78. Suisse: Université de Fribourg.

BOUDREAU, Annette. A construção das representações linguísticas na acádia. Trad. Ana Lúcia Silva Paranhos. In: Interfaces Brasil /Canadá, n. 10, p. 77-108. Rio Grande: ABECAN, 2009. 
BOURDIEU, P. O poder simbólico. Lisboa: Difel, Rio de Janeiro: Bertrand, 1989.

CALVET, L.-J. "Oiapoque /Saint-Georges de l'Oyapoque: effets de marge et fusion des marges en situation frontalière". In: Bulot, T. (Org.) formes et Normes sociolinguistique Ségrégations et discriminations urbaines. Paris: L'Harmattan, p. 15-40, 2009.

DAY, K. A situação sociolinguística da fronteira franco-brasileira: Oiapoque \& Saint Georges. Dissertação (Mestrado em Estudos da Linguagem) - Pontifícia Universidade Católica do Rio de Janeiro, Rio de Janeiro. 2005.

DAY, K. "Fronteiras linguísticas e fronteiras políticas: relações linguísticas e socio-históricas na fronteira do Brasil com a Guiana Francesa”. In: Cadernos de Letras da UFF, Dossiê: Língua em uso, n. 47, p. 163-182. Niterói: UFF, 2013

DAY, K. Repercussões da Lei 11.161/2005 sobre a política linguística da fronteira franco-brasileira. Comunicação oral apresentada no congresso da Abralin. UFPA, Belém: Pará, 2015.

DI MÉO, G. Le territoire: un concept essentiel de la géographie sociale, les documents de la Maison de la Recherche en Sciences Humaines de Caen, n. 7, (Colloque de géographie sociale de Caen d'octobre 1996), 1998.

FISHMAN, J. "A sociologia da Linguagem". In: FONSECA, M. S. V.; NEVES, F. (Orgs). Sociolinguística. Rio de Janeiro: Eldorado, p. 2540, 1974.

FISHMAN, J. "Bilingualism with and without diglossia; diglossia with and without bilingualism". In: Journal of social issues, 23 (2), 29 38. The Society for the Psychological Study of Social Issues, 1967.

FUMELÊ, L.V. da S.; DAY, K. "O contato português-francês e o bilinguismo societal dos catraieiros na fronteira franco-brasileira". In: Revista Sociodialeto, n. 32, v. 11, p. 113-138, 2020.

GAJO, L. "Le discours sur le bilinguisme autour de la frontière linguistique en Suisse. Représentations de frontières et frontières de représentations”. In: Synergies, n ${ }^{\circ}$. p. 37- 45, Sylvains les Moulins, France, 2005.

HALL, Stuart. Da diáspora: identidades e mediações culturais. Organização Liv Sovik; Tradução Adelaine La Guardia Resende et all. - Belo Horizonte: Editora UFMG; Brasília: Representação da UNESCO no Brasil, 2003. 
HAMEL, R. E. 'L'aménagement linguistique et la globalisation des langues du monde". In: Télescope, $n^{\circ} 3$, vol. 16, p. 1-21. Quebec: UNAP, 2010.

HAMERS, J.F.; BLANC, M. H A. Bilingualité et bilinguisme. Bruxelles: Pierre Mardagas Editeur, 1983.

LEGLISE, I. "Langues frontalières et langues d"immigration en Guyane Française: pratiques et attitudes d'enfants scolarisés en zone frontalières". In: Glottopol. n. 4 p. 110- 124. Rouen: CNRS/ DYALANG, 2004.

LEGLISE, I. Multilinguisme, variation, contact. Des pratiques langagières sur le terrain à l'analyse de corpus hétérogènes. Institut National des Langues et Civilisations Orientales- INALCO PARIS LANGUES, 2013.

LEMOS, G. M; DAY, K. "Representação e identidade fronteiriça: um estudo na fronteira franco-brasileira". In: Miguilim - Revista Eletrônica do Netlli, n. 3, v. 9, p. 992-1018, set.-dez, Crato: NETLLI, 2020.

MELLO, H. "Atitudes linguísticas em uma comunidade bilíngue do sudoeste goiano". In: SILVA, S. (Org.). Línguas em contato: cenários de bilinguismo no Brasil. Campinas: Pontes Editores, p.141-178, 2011. MACKEY, W. F. Bilinguisme et Contact des langues. Paris: Editions Klincksieck, 1976.

OLIVEIRA, T. C. M. "Os Elos da Integração". In: OLIVEIRA, M; COSTA, E. (Org.). Seminário de Estudos Fronteiriços. 1 ed., v. 1, p. 25- 44. Campo Grande: Editora da UFMS, 2009.

PEREIRA, Telma. "Fronteira Oiapoque Saint-Georges: línguas e políticas linguísticas em contato". In: SALGADO A. C. P.; BARRETO, M.M.G.S. (Org.). Sociolinguística no Brasil: uma contribuição dos estudos sobre línguas de/em contato. Rio de Janeiro: 7 Letras, p. 177188, 2009.

ROMANI, Carlo. "A história entre o oficial e o lendário: interações culturais no Oiapoque”. In: Antíteses, n. 5, v. 3, p. 145-169, 2010.

SILVA, J. "A cidade de Oiapoque e as relações transnacionais na fronteira Amapá-Guiana Francesa”. In: História Revista, n. 2, v. 10, p. 273-298. Macapá: Unifap, 2005.

SIMMEL G. Sociologie, Études sur les formes de socialisation, Paris: PUF, 1999. 
SOUZA NASCIMENTO, J. L. de; DAY, K. C. N. "Dinâmicas interacionais fronteiriças: o uso do Francês nas instituições públicas em Oiapoque”. In: Macabéa, n. 1, v. 10, p. 315-337. Crato: NETLLI, 2021. SPINASSÉ, K. “Os conceitos Língua Materna, Segunda Língua e Língua Estrangeira e os falantes de línguas alóctones minoritárias no Sul do Brasil". In: Revista Contingentia, Vol. 1, p. 01-10. Rio Grande do Sul: UFRGS, 2006.

SKUTNABB-KANGAS, T. "Multilingualism and the education of minority children". In: SKUTNABB-KANGAS, Tove \& CUMMINS, Jim (Org.). Minority education: fron shame to stryggle. Clevedon: Multilingual Materrs, p. 9-44, 1988.

STURZA, E. R. "Línguas de Fronteira: O Desconhecido Território das Práticas Linguísticas nas Fronteiras Brasileiras”. In: Ciência e Cultura, n.2, v. 57, p. 57-65. São Paulo: SBPC, 2006.

STURZA, E. R. "Espaço de enunciação fronteiriço e processos identitários". In: Pro-Posições, n. 3 (63), v. 21, p. 83-96, set./dez. Campinas: Unicamp, 2010.

STURZA, E. R.; TATSCH, Juliane. "A fronteira e as línguas em contato: uma perspectiva de abordagem". In: Cadernos de Letras da UFF. Dossiê: Línguas e culturas em contato $\mathrm{n}^{\circ}$ 53, p. 83-98. Niterói/UFF, 2016.

VALDES, G.; FIGUEROA, R. "Bilingualism and Testing: A Special Case of Bias". In: STEFANAKIS, E. H. Applied psycholinguistics. n.2, v. 21, p. 290-300. Norwood, NJ: Ablex Publishing, 1994.

WEINREICH, U. Languages in contact: finding and problems. Haia: Mouton, $7^{\mathrm{a}}$ ed. 1970.

\section{Notas}

* Graduada em Letras português-francês pela Universidade Federal do Pará (UFPA). Tem especialização em tradução português-francês pela Universidade do Estado do Rio de Janeiro (UERJ); Mestrado em Estudos da Linguagem pela Pontifícia Universidade Católica do Rio de Janeiro (PUC-Rio); Doutorado em Estudos da linguagem pela Universidade Federal Fluminense (UFF). Atualmente, é professora adjunta na Universidade do Estado do Amapá (UEAP). 
${ }^{1}$ Após mais de 200 anos de disputa, em 1900, a arbitragem suíça do litígio entre Brasil e França estabeleceu o limite, entre o Brasil e a Guiana Francesa, no rio Oiapoque como defendia o Brasil.

2 Adota-se neste trabalho a noção de espaço social delimitada por Bourdieu, que abrange as interações estabelecidas na confluência de lugar, de sociedade e de cultura. Para Bourdieu, as distâncias espaciais entre os diferentes grupos, com marcações distintas de pertencimento, expressam as distâncias sociais.

3 O Kheuól é considerado uma variedade do crioulo guianense utilizado pelas populações indígenas Karipuna e Galibi Marworno, nos dois lados da fronteira.

${ }^{4}$ Créole Guianense é um crioulo de base francesa, amplamente utilizado como língua veicular em toda a Guiana Francesa, pela população nativa.

${ }^{5} \mathrm{O}$ regime de assistência social e subvenção às populações carentes e indígenas (RSARevenu de Solidarité Active) no lado francês, configura-se atrativo para a migração em direção à Guiana Francesa.

${ }^{6}$ Transporte fluvial através do qual circulam pessoas e mercadorias entre as fronteiras;

${ }^{7}$ Na região de Oiapoque há registro de 2 línguas consideradas indígenas: o Kalinã falado pela etnia Galibi-Kalinã e o Parikwaki utilizado pela etnia Palikur.

${ }^{8}$ De acordo com Valdés e Figueroa, o bilinguismo eletivo é aquele em que o indivíduo se torna bilíngue por escolha, ou seja, quando há um desejo de aprender outra língua a fim de realizar viagens, estudos, conhecer outra cultura, etc.

${ }^{9}$ As noções de língua materna, segunda língua e língua estrangeira aplicadas neste texto remetem àquelas desenvolvidas por Spinasse (2006), para quem língua materna se relaciona tanto a aspectos cronológicos quanto identitários e afetivos; segunda língua ou L2 é "uma não primeira-língua" adquirida pela necessidade de comunicação, em um contexto de socialização que inclui entre outros fatores, "um contato mais intensivo com a nova língua que seja importante para a comunicação e integração social" (p.6); e língua estrangeira é concebida como língua exógena ao ambiente e o processo de aprendizagem se estabelece em ambientes formais de aprendizagem.

${ }^{10}$ Paisagem linguística é um conceito introduzido por Landry e Bourhis (1997) no âmbito da Sociolinguística urbana que aborda a utilização de textos escritos em espaços públicos.

${ }^{11}$ Para a noção de diglossia, utiliza-se a acepção de Fishman (1967; 1974, p. 111) que a compreende como "uma situação lingüística relativamente estável na qual, além da ou das variedades adquiridas em primeiro lugar (variedades que podem conter um padrão ou vários padrões regionais), se encontra também uma variedade sobreposta, muito divergente e altamente codificada, por vezes mais complexa ao nível gramatical" (...).

${ }^{12}$ As denominadas "allocations familiales" são subvenções recebidas pelas famílias de baixa renda, que visam, entre outros aspectos, a manutenção dos filhos na escola. 